\title{
Analysis of Airflow Field of Toss Device of Yellow Corn Forage Harvester
}

\author{
Yan Huang ${ }^{1}$, Manquan Zhao ${ }^{1, *}$ and Hantao Liu $^{2}$ \\ ${ }^{1}$ Mechanical and Electrical Engineering College of Inner Mongolia Agricultural University, \\ Hohhot 010018 , China \\ ${ }^{2}$ Food Science and Engineering College of Inner Mongolia Agricultural University, \\ Hohhot 010018, China \\ \{wuxinglaozu, nmgzhaomq\}@163.com, 28715369@qq. com
}

\begin{abstract}
Use a very important tool called ICEM CFD integrated in ANSYS Workbench to mesh the model of toss device and then apply the software FLUENT to simulate numerically and analyze the velocity distribution and pressure distribution, based on the RNG k-epsilon model. Numerical simulation results showed that air flow field and pressure distribution of toss device were asymmetry. Maximum wind speed of fan exit was $42.8 \mathrm{~m} / \mathrm{s}$, which met the actual needs. In a word, the design of toss device was reasonable. But there was the existence of the secondary flow in toss cylinder, making some gas couldn't flow smoothly, thus affecting delivery efficiency. Through analysis of the stress field in the blower, the results showed that static pressure of windward side blade increased from roots to ends and flow channels between fan blades in different positions showed different static pressure characteristics. The maximum static pressure of windward side blade was $878 \mathrm{pa}$, the minimum static pressure of lee side blade just passing the export of fan was $-950 \mathrm{pa}$, the negative pressure meaning suction. The conclusions provided a reference for structural optimization and performance improvement of the toss device of Yellow Corn Forage Harvester .
\end{abstract}

Keywords: Forage harvester, ANSYS FLUENT, Air flow field, Numerical simulation.

\section{$1 \quad$ Introduction}

Crop straw resources in China were very rich, containing large amounts of corn straws[1-3]. 9HS-170 type Yellow Corn Forage Harvester was united harvest machine which was mainly used for sequential feeding, chopped, propulsion and toss loading corn stalk .

The working subassembly contained roll device, toss device, pressure device, as well as transmission system and propulsion system etc. Toss device was the core part of the machine. Its working principle was that the material delivered by the screw

\footnotetext{
* Corresponding author.
} 
conveyor were threw along toss cylinder from exit under the action of high speed rotation blade. The main existing problems of toss device were big power consumption and low efficiency. In order to reduce the power consumption of toss device and improve the efficiency of toss. Scholars both at home and abroad did a number of studies[4-8].

In recent years, with the development of computational fluid dynamics, CFD technology replaced the classical fluid mechanics of some approximate calculation method and graphic method. Facing fluid flow within the fluid machinery problems of fan and pump, in the past mainly by means of the basic theoretical analysis and lots of physical model experiment, now mostly adopt the way of CFD. CFD technology has now reached the level of analyzing and solving complex problems such as $3 \mathrm{D}$ viscous turbulent flow and vortex motion [9-11].

The paper used software of Soildworks to establish the three-dimensional model and used software of ICEM CFD to mesh toss devices by unstructured tetrahedral and evaluate the quality of the grid. Finally, use ANSYS FLUENT 12.1 to simulate numerically its internal flow field, so as to understand the distribution law of flow field and provide theoretical basis for optimization design personnel, making up for the deficiency of the traditional experiment.

\section{The Mathematical Model}

The choice of turbulence model had a great influence on the result when analyzing the air flow field of toss device. General numerical calculation methods were broadly divided into the following three categories: Direct Numerical Simulation, Reynolds Averaged Navier-Stokes, Large Eddy Simulation. Among two equation model K-epsilon Model included Standard k-epsilon Model, RNG k-epsilon Model, Realizable k-epsilon Model. Standard k-epsilon Model was stable and relatively accurate, which was widely used in engineering application. RNG k - epsilon model was similar to the standard k-epsilon (SKE) model in the form. It made improvements in the following areas compared with the standard $\mathrm{k}-$ model [12]:

(1) RNG model added a condition to the epsilon equation, which effectively improved the accuracy.

(2) The model took the turbulent vortex into account and improved the accuracy in this respect.

(3) RNG theory for turbulent Prandtl number provided an analytical formula, however , Standard k - epsilon model used a constant that the user provided.

(4) Standard k - epsilon model was a model of high Reynolds number, RNG theory provided an analytical formula considering low Reynolds number flow viscosity.

These features made RNG k - epsilon model had higher reliability and accuracy than Standard k - epsilon model.

The paper selected RNG k-epsilon model, which had better performance in simulating complex flow such as jet impact, separated flow, secondary flow, rotating flow in order to understand movement regularity of air flow field of the toss device better. 


\section{$3 \quad$ Multiple Reference Frame and the Boundary Conditions}

Multiple reference frame (MRF) model was used to solve periodic rotation in the case of a transient when analyzing air flow field of toss device[13]. Otherwise, set rotating area parameters in the software of Fluent, including motion type, which was the moving reference frame and the rotation axis position measured in the ICEM CFD. The other important conditions such as the rotation speed was $1270 \mathrm{rpm}$ as well as defining the interface between static domain and rotating domain, the entrance boundary condition was pressure inlet, the exit boundary condition was pressure outlet, at the same time, setting the wall of fan blades was movement. Its rotating speed was zero relative to the speed of the rotating field.

\section{$4 \quad$ Physical Model and Numerical Calculation Method}

Create and assemble components such as fan and shell and toss cylinder, etc. based on structure size of toss device and then handle and simplify model appropriately. The simple structure model of toss device was shown in Fig.1. After that the model was imported into the ICEM CFD in order to be meshed by unstructured tetrahedral grid. At the same time, set the static field and rotating field and the location of the inlet and outlet. The calculation method was Semi-Implicit Method for Pressure-Linked Equations (SIMPLE), interpolation method of the convection item was the First - Order Upwind, which was easy to converge[13].

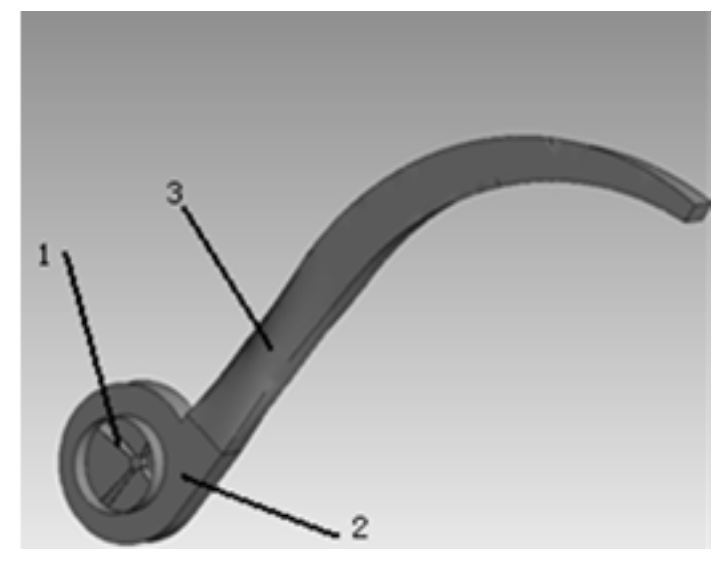

1.Blade 2. Fan shell 3.Toss cylinder

Fig. 1. 3D entity model of toss device

\section{$5 \quad$ Numerical Simulation and Analysis}

After 607 times of iterative computation, the results converged and its convergence precision was 1e-3. 
As can be seen from the velocity vector plot (Fig.2), the wind speed near the end of the blade was between $35.7 \sim 42.8 \mathrm{~m} / \mathrm{s}$, close to the theoretical calculation value of 40 $\mathrm{m} / \mathrm{s}$, indicating the model was correct and the data was reliability. In addition, when the blower working normally, the speed of the middle area was smaller than the edge and the maximum speed existed in the area between blade and shell was $42.8 \mathrm{~m} / \mathrm{s}$, meeting the design requirement. Furthermore, as shown in Fig.3, there was gas reflux in the middle part of toss cylinder, effecting the toss efficiency. Optimizing personnel may appropriately change related parameters of toss device, making the effect of negative impact minimize as well as reducing noise.

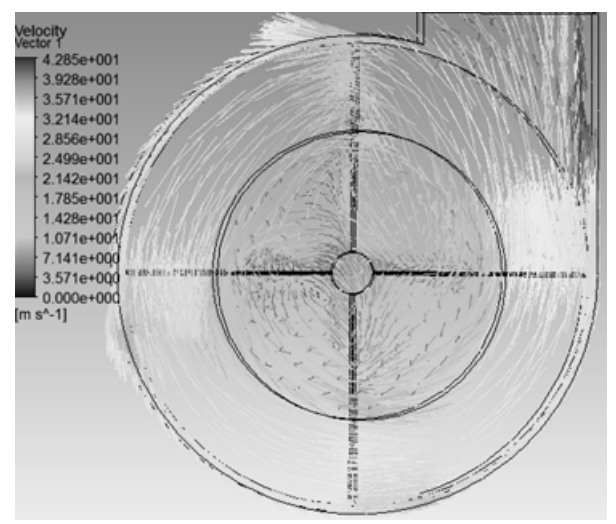

Fig. 2. Velocity vector plot of the blower

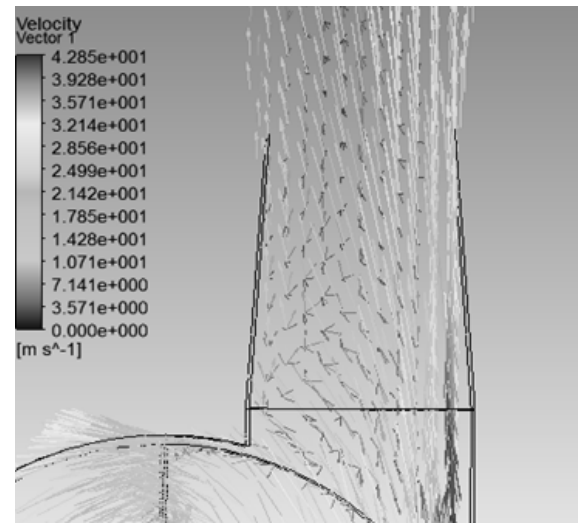

Fig. 3. Velocity vector plot of toss cylinder

As shown in Fig.4 and Fig.5, static pressure of windward side of blade increased from roots to ends, the maximum static pressure at the end of the windward side of blade surface was 878 pa. The minimum static pressure of lee side blade just passing the export of fan was $-950 \mathrm{pa}$, the negative pressure meaning suction.

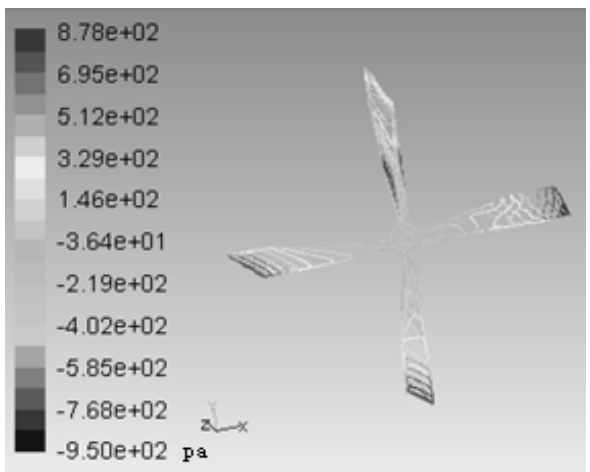

Fig. 4. Static pressure contour of blade

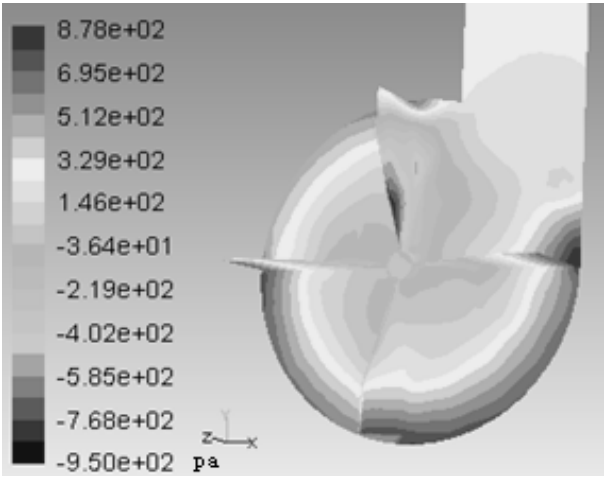

Fig. 5. Static pressure contour inside the blower 
Flow channels between fan blades in different positions showed different static pressure characteristics. Static pressure of flow channels that were gradually far from the exit decreased and static pressure of flow channels that were gradually close to the exit increased. The distribution was stronger asymmetry. According to pressure distribution of blade, maximum stress concentrated at root and ends of blade ,so the structural at root and ends of blade needed to be strengthened in order to improve the service life.

\section{Conclusions}

Airflow Field of Toss Device of Yellow Corn Forage Harvester was very complicated.

More information could be gotten by numerical simulation, compared with the traditional experimental analysis, using the software of ANSYS FLUENT :

1 Maximum wind speed of fan exit was $42.8 \mathrm{~m} / \mathrm{s}$,meeting design requirement, simulation results were close to the theoretical calculation results compared with the theoretical calculation value, verifying the validity of the model selection and illustrating the design of toss device were rationality.

2 Through the analysis of the velocity field inside toss device, there was gas reflux in the middle part of toss cylinder, effecting the toss efficiency. Optimizing personnel may appropriately change relative parameters of toss device to make the effect of negative impact minimize.

3 Through the analysis of the stress field inside toss device, finding the value of static pressure was asymmetry, illustrating that pressure distribution was associated with the geometric size of fan exit and blade shape.

Acknowledgements. Fund origin of this project: The Inner Mongolia Autonomous Region Technology Innovation projects ( 20101734 ) , The Inner Mongolia Agricultural University Technology Innovation Team projects (NDPYTD2010-8).

\section{References}

1. Gao, X., Ma, W., Ma, C., et al.: Analysis on the Current Status of Utilization of Crop Straw in China. Journal of Huazhong Agricultural University 21(3), 242-247 (2002) (in Chinese)

2. Cui, M., Zhao, L., Tian, Y., et al.: Analysis and evaluation on energy utilization of main crop straw resources in China. Transactions of the CSAE 24(12), 291-296 (2008) (in Chinese)

3. Gao, L., Ma, L., Zhang, W., et al.: Estimation of nutrient resource quantity of crop straw and its utilization situation in China. Transactions of the CSAE 25(7), 173-179 (2009) (in Chinese)

4. Zhai, Z., Gao, B., Yang, Z., et al.: Power consumption and parameter optimization of stalk impeller blowers. Transactions of the Chinese Society of Agricultural Engineering. Transactions of the CSAE 29(10), 26-33 (2013) (in Chinese)

5. Chancellor, W.J.: Influence of particle movement on energy losses in an impeller blower. Agricultural Engineering 41(2), 92-94 (1960) 
6. Shinners, K.J., Koegel, R.G., Pritzl, P.J.: An upward cutting cut-and-throw forage harvester to reduce machine energy requirements. Transactions of the ASAE 34(6), 2287-2290 (1991)

7. Zhai, Z., Wang, C.: Numerical Simulation and Optimization for Air Flow in an Impeller Blower. Transactions of the Chinese Society for Agricultural Machinery 39(6), 84-87 (2008) (in Chinese)

8. Song, J., Liu, Y., Ma, W., et al.: Internal flow field simulation and structure parameters optimization of centrifugal fan of snow remover. Transactions of the Chinese Society of Agricultural Engineering. Transactions of the CSAE 1(3), 83-87 (2011) (in Chinese)

9. Li, G., Wang, Y., Lü, X., et al.: Numerical simulation of three-dimensional flow field in centrifugal pump with deviated short splitter vanes. Transactions of the CSAE 27(7), 151-155 (2011) (in Chinese)

10. Li, X., Yuan, S., Pan, Z., et al.: Numerical simulation of whole flow field for centrifugal pump with structured gird. Transactions of the Chinese Society for Agricultural Machinery 44(7), 50-54 (2013) (in Chinese)

11. Huang, S., Wang, G.: Analysis of flow field asymmetry and force on centrifugal pump by 3-D numerical simulation. Transactions of the Chinese Society for Agricultural Machinery 37(10), 66-69 (2006) (in Chinese)

12. Wu, G., Song, T., Zhang, Y.: FLUENT introductory and proficient in case, pp. 38-39. Publishing House of Electronics Industry, Beijing (2012) (in Chinese)

13. Wei, L., Weidong, S., Xiaoping, J., et al.: Numerical calculation and experimental study of axial force on multistage centrifugal pump. Transactions of the CSAE 28(23), 52-59 (2012) (in Chinese) 